\title{
Students Perception towards Problem Based Learning
}

\author{
Dr Sushil P Dube ${ }^{1}$, Dr Manik S Ghadlinge ${ }^{2}$, Dr Mungal S.U ${ }^{3}$, Dr Saleem B \\ Tamboli ${ }^{4}$, Dr Mukund B Kulkarni ${ }^{5}$. \\ ${ }^{1,3,5}$ (Assistant Professor, Department of Physiology, Dr. Shankarrao Chavan Government Medical College, \\ Nanded. Maharashtra. India.) \\ ${ }^{2}$ (Assistant Professor, Department of Pharmacology, Dr. Shankarrao Chavan Government Medical College, \\ Nanded. Maharashtra. India.) \\ ${ }^{4}$ ( Associate Professor, Department of Pharmacology, Dr. Shankarrao Chavan Government Medical College,
} Nanded. Maharashtra. India.)

\begin{abstract}
The purpose of this study was to determine student perceptions of the methods used to teach pharmacology via problem-based learning (PBL). To improve problem solving skills and link basic sciences to clinical practice, medical educators have turned to problem based learning as a partial replacement for traditional didactic lectures approach. PBL is an instructional method that uses cases or problems as vehicles for students to acquire critical thinking and problem-solving skills. In problem-based learning, new knowledge is acquired in the context of some meaningful problems or situation. Using likert scale we assessed the students' perceptions of pharmacology education and learning of pharmacology concepts through PBL. Survey responses were anonymous, and results were reported as aggregate data. The survey statements were answered on a fivepoint Likert scale with 1 indicating strong disagreement and 5 indicating strong agreement. Via a ten-question $M C Q$ instrument, students performance was assessed. In our study there was significant increase in performance of students after PBL sessions. Student's feedback shown that PBL enhanced their understanding in Pharmacology, motivated them to read more as well as developed self directed and problem solving attitude in them. Most of students suggested to continue PBL sessions but don't want to replace all didactic lectures by PBL sessions.
\end{abstract}

Keywords: didactic lectures, pharmacology, problem based learning, teaching learning methods

\section{Introduction}

Pharmacology is considered as paraclinical subject which is link between basic sciences and clinical sciences. Traditionally, undergraduate pharmacology education has consisted primarily of didactic lectures i.e. knowledge-based teaching. Medical students must memorize numerous detailed facts about drugs and pharmacological active substance without a direct clinical context. The pharmacology books are too drug concentrated and clinical guidelines more disease oriented. That's why particular therapies are chosen remains unclear to students. Clinicians are entering in practice without appropriate problem solving or clinical decision making skills. Moreover there is informative explosion in the form of newer drugs and various guidelines for medical therapy of diseases. Thus teacher centered education model do not provide optimal opportunities to learn processes needed to identify and treat drug related problems confronting today's practicing clinicians. Therefore traditional learning strategies will not be adequate to cope with these changing demands in medical education.[1]

Considering the current trend for curriculum revision of medical education, traditional lecture based learning has been criticized as lacking the ability to connect basic sciences with clinical sciences. [2-3] To improve problem solving skills and link basic sciences to clinical practice, medical educators have turned to problem based learning (PBL) as a partial replacement for traditional didactic approaches to teach basic and clinical sciences. Instead of traditional lecture based format, students learn by solving problems. Instead of sitting in class taking lecture notes, students take active responsibility for their learning in the student centered, problem based format.[4] Recently, problem based learning (PBL) has emerged as effective method for more active student participation and more clinical oriented method in medical education. [2, 3, 5]. WHO, in reorientation program on medical education, suggested that the introduction of implementation of innovative, problem based learning methods would be preferred to conventional teaching by didactic lectures.[6]

In order to improve the health standards, there is a demand to reform medical schools', curriculum and educational methods in order to enable them to provide integrated health care services. Therefore, medical educators are being encouraged with new learning methods to meet expanded needs. Problem-based learning (PBL) is possibly one of the most innovative methods in medical training. And PBL as an educational method is gaining ground in higher education. 
Problem based learning is a learning process based on the principle of using problems as a starting point for the acquisition and integration of new knowledge [7]. PBL is an instructional method that uses cases or problems as vehicles for students to acquire critical thinking and problem-solving skills. In problem-based learning, new knowledge is acquired in the context of some meaningful problems or situation. PBL was first introduced at McMaster University Medical School in Canada in 1960s. [8] Since then Problem-based learning (PBL) is becoming widely used across a considerable range of subjects and professional areas in higher education.

In PBL students are assigned to groups of $8-10$, and each group is assigned a faculty member who plays the role of a tutor or facilitator as the students work through a case or a problem. This model is very student-centred. Teacher or tutor acts as facilitator of information rather than as a direct source of information. PBL allows students to learn study material by applying processes of reasoning rather than by mere memorization of facts. PBL is a powerful class room process, which uses real-world problems to motivate students to identify and apply research concepts and information, work collaboratively and communicate effectively. It is a strategy that promotes life-long habits of learning. Active learning is the most effective technique for students to learn, apply, integrate, and retain information. PBL is active and applied rather than passive and absorbed. [9] In the PBL approach, complex, real-world problems are used to motivate students to identify and research the concepts and principles they need to know to work through those problems. Thus PBL helps in developing various skills in students like team work, self directed learning, problem solving attitude, communication, interpersonal relationships [10-12]. There is evidence that PBL students are better prepared to apply basic science concepts in clinical sciences. Also they can retain knowledge for longer duration and are better prepared for lifelong learning.

Medical students all over India have to go through several numbers of didactic lectures during their undergraduate course. This teacher centered approach though widely followed, it is having certain drawbacks. Moreover medical students need to go on learning newer and newer things throughout their life. Thus medical students should be encouraged for active learning during their undergraduate education so as to cultivate healthy habits in them. Problem based learning facilitates initial acquisition and subsequent use of an integrated basic and clinical science knowledge base, which is thought to foster development of clinical reasoning skills.

So this study is conducted to introduce PBL as innovative teaching learning method in Pharmacology at Dr Shankarrao Chavan Government Medical College, Nanded and to obtain students feedback in order to provide insights for the future modification in medical education curriculum.

\section{Materials and Method}

Present study was carried out in Dept Of Pharmacolgy, Dr.Shankarrrao Chavan Government Medical College,Nanded,Maharashtra for the IInd M.B.B.S. of batch 2012.

Permission from Head of Department \& ethical committee approval was taken. An orientation of the teachers and students to PBL was done. Teachers interested in medical education innovation were included in the study as tutors/Facilitators. The Facilitators were briefed about PBL and its methodology and benefits as well as their role as facilitator. The Tutors were also briefed about making their sessions interactive and not teacher centered lectures.

A Problem based on applied aspect of Hypertension was constructed by consensus of all faculties. The specific learning objectives were also set by consensus of all faculties. All willingly participated students were included into the study. Informed written consent was taken from all students. The class was then divided into small groups of 10 students each. A Pre-PBL test consisting of 10 MCQ was conducted to assess the knowledge and understanding about the given topic. Then Problem was posed to all groups.

In the first session, group discussed the problem and tried to extract the learning areas for study from textbooks or other resource material, subject experts etc. During this session, the case was discussed through 'triggers'. The group elaborates on the trigger and find out list of learning issues. They were then guided to outline important learning objectives by facilitator. Then the students went home and studied different areas of learning, they have identified during session. After3-4 days in next session, students discussed the facts they studied about the problem and analyzed if there was any learning area which require more study. Again they read about learning area and discuss among themselves after few days. These sessions were repeated till they satisfied about solution of problem.

In all groups there was one leader, one time keeper, one recorder, one reporter and a tutor as facilitator. In these sessions, the students sit in circle to maintain eye to eye contact and they follow the rules of group dynamics. The group leader ensured active participation of each group member and the tutor or facilitator provide input where required.

The same Pre PBL MCQ test was repeated after PBL sessions to evaluate knowledge gained. Feedback was taken from students by providing pretested and validated questionnaires. Feedback included constructed 
response with open ended questions and selected response with Likert scale. The responses were measured in term of - Don't agreed, somewhat agreed, agreed, strongly agreed, neutral.

\section{Statistical analysis}

Total 50 students participated in this study and given their feedback. Obtained Data was analyzed by using statistical software Open Epi Version 2.3. Comparison of Pre PBL and Post PBL score was done using paired 't' test. Feedback questions were analyzed using percentages.

\section{Results}

Most of students opined that PBL sessions helped them in learning pharmacology. Nearly fifty percent students agreed that PBL improved ability to apply concepts of basic sciences to clinical situations. More than Fifty percent opined that PBL studies reinforced information taught in other classes and PBL increased their involvement in teaching learning process. Almost Fifty percent students stated that PBL sessions will be helpful for final university exam preparation. All of the students agreed that learning of facts, diagnostic and therapeutic skills were significantly enhanced by PBL sessions. The PBL sessions enhanced my clinical reasoning abilities were stated by more than ninety percent of students. Most of the participants opined that the PBL sessions improved their skills in teaching themselves new materials. Nearly sixty percent students suggested replacement of tutorial classes by PBL.

In comment received by students they stated that in PBL sessions there was active participation of each group member and PBL helps in understanding topic in different and better way because of active discussion among group members.

\section{Discussion}

Historically knowledge was acquired by word of mouth from one generation to the next. Eventually the printing press and books made knowledge more accessible. As a result of technological advances in the $20^{\text {th }}$ century, knowledge acquisition and transmission have seen a logarithmic increase. The information available is so plentiful and changing so rapidly that most individuals will encounter only a small portion of it. If students are going to be capable of making informed decisions that result in reasonable actions, they will need more than facts. Students need to recognize what information is needed, have the knowledge and skill necessary to acquire this information and the ability to use that knowledge appropriately to solve the problems they face.

Finding the right answer to a problem or applying what has already been learned to a problem is not problem based learning. In problem-based learning, the "problem" serves as a stimulus and focus for students to identify what they need to learn in order to understand the problem and also to learn about the broader concepts and principles related to the problem. The problem is used as a springboard for learning, and the more appropriate term for this form of learning would be "contextual learning". [13] Problem-based learning is teaching learning method in which learning is stimulated and motivated by the learner's encounter with problems. Nowadays PBL based teaching-learning methods are being incorporated in medical education curriculum at various medical universities. But still debate continues on merits of PBL over traditional teaching learning methods.

In addition to learning core competencies of the medical subjects, medical students need to get evolved in various fields of interpersonal relationships, communication, group activities. And this is the area where PBL stands out from traditional Teaching-Learning methods. Morrison JM stated that, it is possible to introduce problem- based learning into new curriculum parallel with traditional modes of teaching.[14]. PBL does not appear to hamper knowledge acquisition and may develop characteristics that result in 'better' clinicians postgraduation. Woodward (1990) found favorable trends for interns from a PBL school with respect to supervisor ratings [15]. Hoffman et al. (2006) found gains in residency performance, such as improved communication and collaboration skills, maturity, and initiative [16]. In contrast, Santos-Gomez et al. (1990) found no significant differences overall in residency performance as rated by either nurses or doctor-supervisors.[17].

PBL instruction addresses several desirable outcomes of an undergraduate education, particularly critical thinking, research skills, communication skills, and other lifelong learning skills. PBL strategy is remarkably adept and adaptable vehicle to develop in students, core knowledge in a content area, cognitive skills (analysis, synthesis, application, evaluation, and critique) and action skills (organizing time, resources, coordination, negotiating, tolerating).[9]

In our study there is significant increase in performance of students after PBL sessions. Student's feedback shown that PBL enhanced their understanding in Pharmacology, motivated them to read more as well as developed self directed and problem solving attitude in them. Most of students suggested to continue PBL sessions but don't want to replace all didactic lectures by PBL sessions. Also post PBL MCQ score are significantly better as compared to pre PBL score. But to evaluate student's performance long term \& multicentre studies are required. 
The major problem encountered in conducting PBL was that it was consuming more time. The same opinion is expressed by O'Hanlon et al [18]. Also more teachers were needed as the students were divided in small batches. Along with time restriction, poor student motivation, evaluation problems were also the problems encountered. These problems can be solved by training the staff in conducting PBL. Introduction of PBL in conventional medical curriculum encourages both the teachers and students to experiment with a new approach to learning. Whether PBL is adequate to cover the numerous facts that students needs to memorize in pharmacology presents another concern. It is considered that memorizing \& recollection of drug name and fact depends a lot on individual capacity.

Nandi et al stated that a combination of both traditional teaching and PBL may provide the most effective training for undergraduate medical students. [19] Thus if both these educational approaches i.e. traditional and PBL are combined together, it will help students to actively learn and enhance their ability to answer clinical problems.

\section{Conclusion}

In accordance with student's feedback about PBL, it should be continued in Pharmacology. Teachers' training is needed for effective PBL sessions. The objective analysis of effectiveness of PBL can be made by evaluating students' performance over one academic year with and without PBL. Though PBL sessions were found effective here but there are concerns regarding its overall effectiveness. Teaching Learning method which is suitable for one set of student population doesn't mean that it will be accepted by all. Combination of both methods didactic lectures \& case studies based on problem based learning will be an effective educational tool. But considering objective nature of postgraduate entrance examinations in India, problem based learning methods will stimulate more active learning by students.

Table 1. Comparison between Pre PBL and Post PBL score

\begin{tabular}{|c|c|c|c|c|}
\hline \multicolumn{5}{|c|}{ Paired ' $t$ ' test analysis for Pre PBL \& Poat PBL test Score } \\
\hline & $\mathrm{N}$ & Mean & SD & $P$ value \\
\hline Pre PBL test Score & 50 & 3.64 & 0.80 & \multirow[b]{2}{*}{$P$ value $<0.0001$} \\
\hline Post PBL test Score & 50 & 6.16 & 1.14 & \\
\hline
\end{tabular}

Where N- number of students \& SD- Standard Deviation \& ( $p$ value $<0.001-$ Highly Significant)

Table 2. Likert scale

\begin{tabular}{|c|c|c|c|c|c|c|}
\hline & & $\begin{array}{l}\text { don't } \\
\text { agree }\end{array}$ & $\begin{array}{l}\text { somewhat } \\
\text { agree }\end{array}$ & agree & $\begin{array}{l}\text { strongly } \\
\text { agree }\end{array}$ & Neutral \\
\hline 1 & $\begin{array}{l}\text { The PBL improved my ability to apply concepts of } \\
\text { basic sciences to clinical situations. }\end{array}$ & $2(4 \%)$ & $8(16 \%)$ & $\begin{array}{l}20 \\
(40 \%)\end{array}$ & $20(40 \%)$ & 0 \\
\hline 2 & Replacement of tutorial classes by PBL sessions.. & $8(16 \%)$ & $20(40 \%)$ & 14(28\%) & $3(6 \%)$ & $\begin{array}{l}\mathbf{5} \\
(10 \%)\end{array}$ \\
\hline 3 & $\begin{array}{l}\text { The PBL studies reinforced information taught in } \\
\text { other classes. }\end{array}$ & $5(10 \%)$ & $6(12 \%)$ & $16(32 \%)$ & $23(46 \%)$ & 0 \\
\hline 4 & $\begin{array}{l}\text { My learning of facts, diagnostic and therapeutic } \\
\text { skills were significantly enhanced by PBL sessions }\end{array}$ & $3(6 \%)$ & $8(16 \%)$ & $16(32 \%)$ & $33(66 \%)$ & 0 \\
\hline 5 & $\begin{array}{l}\text { PBL sessions will be helpful for final university } \\
\text { exam preparation. }\end{array}$ & $13(26 \%)$ & $6(12 \%)$ & $12(24 \%)$ & $19(38 \%)$ & 0 \\
\hline 6 & $\begin{array}{l}\text { The PBL sessions improved my skills in teaching } \\
\text { myself new materials. }\end{array}$ & $12(24 \%)$ & $9(18 \%)$ & $14(28 \%)$ & $11(22 \%)$ & $4(8 \%)$ \\
\hline 7 & $\begin{array}{l}\text { The PBL sessions helped me develop skills in } \\
\text { identifying potential drug related difficulties of the } \\
\text { patient. }\end{array}$ & $2(4 \%)$ & $4(8 \%)$ & $12(24 \%)$ & $32(64 \%)$ & 0 \\
\hline 8 & $\begin{array}{l}\text { PBL increases your involvement in teaching } \\
\text { learning process }\end{array}$ & $3(6 \%)$ & $1(2 \%)$ & $7(14 \%)$ & $39(78 \%)$ & 0 \\
\hline 9 & $\begin{array}{l}\text { I feel confident in applying basic science } \\
\text { knowledge to the solution of clinical problems. }\end{array}$ & $5(10 \%)$ & $16(32 \%)$ & $24(48 \%)$ & $5(10 \%)$ & 0 \\
\hline 10 & $\begin{array}{l}\text { PBL session helps in memorizing drug names \& } \\
\text { classification }\end{array}$ & $3(6 \%)$ & $40(80 \%)$ & $2(4 \%)$ & $5(10 \%)$ & 0 \\
\hline 11 & $\begin{array}{l}\text { The PBL sessions enhanced my clinical reasoning } \\
\text { abilities. }\end{array}$ & $4(8 \%)$ & $2(4 \%)$ & $6(4 \%)$ & $38(4 \%)$ & 0 \\
\hline 12 & $\begin{array}{l}\text { The PBL sessions helped me in learning } \\
\text { pharmacology. }\end{array}$ & $1(2 \%)$ & $3(6 \%)$ & $4(8 \%)$ & $428(4 \%)$ & 0 \\
\hline & Drawbacks of PBL & \multicolumn{5}{|c|}{$\begin{array}{l}\text { Time consuming, Required more number of faculties, needs } \\
\text { motivated students, problems among group members, tutors } \\
\text { role etc }\end{array}$} \\
\hline
\end{tabular}




\section{References}

[1]. Hudec R,Tisonova J,Bozekova L, Wawruch M, Kriska M, Kristova V Modified Problem-based learning in Pharmacology Bratisl Lek Listy. 2009; 110(11): 732-735

[2]. Regan-Smith MG,Obenshain SS, Woodward C, Richards B, Zeitz HJ, Small PA. Rote learning in medical school. JAMA 1994;272:1380-1

[3]. Vernon DT,Blake RL. Does problem based learning work?A meta-analysis of evaluative research.Acad Med 1993;68:550-63.

[4]. The Use of Student-Centered, Problem-Based, Clinical Case Discussions to Enhance Learning in Pharmacology and Medicinal Chemistry1: Richard N. Herrier, Terrence R. Jackson and Paul F. Consroe; American Journal of Pharmaceutical Education Vol. 61, Winter 1997.

[5]. Lau YT. Problem -based learning (PBL) in Physiology:a survey of department heads in medicalschool in Taiwan. J Med Edu 2002; 6:488-91.

[6]. WHO. Reorientation of medical education. Introducing problem based learning in OSE Asia region. Regional publication SEARO :New Delhi ; 1992.

[7]. Barrows H, Tamblyn R. 1976. An evaluation of problem-based learning in small groups utilizing a stimulated patient. J Med Edu 51:52-54.

[8]. Schwartz P, Mennin S and Webb G. Problem -based learning case studies, experience and practice. Routeledge Taylor and Francis group.London. 2006;1-3.

[9]. 9.Bader Shamsan and A.T. Syed: Evaluation of Problem Based Learning Course at College of Medicine, Qassim University, Saudi Arabia: International Journal of Health Sciences, Qassim University, Vol. 3, No.2, (July 2009/Jamada II 1430H))

[10]. Alper A. Attitudes Towards Problem -based learning in a New Turkish Medical Curriculum. World Applied Sciences Journal.2008;(6): 830-836.

[11]. Elsie KM, Francis B, Gonzaga MA. Attitudes and perception of students and teachers about Problem -based learning in the radiography curriculum at Makerere University,Uganda. European Journal of Radiography.2009;1:156-162.

[12]. Tavare V. PBL in physiotherapy: A review of perception and attitude of students.Pacific Public health. 2006;13(2):137-139.

[13]. Rangachari P. K. Design of aproblem-based undergraduate course in pharmacology: implications for the teaching of physiology. Am. J. Physiol. 260 (Adv. Physiol. Educ. 5): S14-S21, 1991.

[14]. Morrison JM, Murray Ts. An experiment in Problem -based learning. Med Edu,28,1994 139-145.

[15]. Woodward C.1990. Monitoring an innovation in medical education: The Mc Master experience. In: Nooman ZM, Schmidt HG, Ezzat ES, editors. Innovation in medical education: An evolution of its present status. New York: Springer. pp 27-39.

[16]. Hoffman K, Hosokawa M, Blake Jr R, Headrick L, Johnson G. Problem based learning outcomes:Ten years of experienceat the university of Missouri-collumbai school of Medicine.Acad Med 2006 81(7):617-625.

[17]. Santos-Gomez L, Kalishman S, Rezler A, Skipper B, Mennin SP.1990 Residency performance of graduates from a problem based and a conventional curriculum.Med Educ 24(4) 366-375.

[18]. O'Hanlon A,Winefield H, Hejka E, Chur-Hansen A. Initial responses of first-year medical students to problem-based learning in a behavioural science course: role of language background and course content. Med Educ.1995 May; 29(3):198-204.

[19]. Nandi PL, Chan JN, Chan CP, Chan P, Chan LP. 2000. Undergraduate medical education: comparison of problem-based learning and conventional teaching. Hong Kong Med J 6:301-306. 